\title{
Section introduction \\ Introduction to sessions on 'What can surgeons do for us (and we for them): radiology, pathology, molecular biology and local therapy'
}

\author{
J Michael Dixon ${ }^{1}$ and Monica Morrow ${ }^{2}$
}

${ }^{1}$ Edinburgh Breast Unit, Western General Hospital, Edinburgh EH4 2XU, UK

2Breast Service, Memorial Sloan-Kettering Cancer Center, York Avenue, NY 10065, USA

Corresponding author: J Michael Dixon, mike.dixon@ed.ac.uk

Published: 18 December 2008

This article is online at http://breast-cancer-research.com/content/10/S4/S2 (c) 2008 BioMed Central Ltd

A number of important issues surrounding local control of breast cancer continue to attract debate. In breast conserving surgery, the balance between excising sufficient tissue to achieve a satisfactory cosmetic outcome while also achieving adequate long-term local control remains an issue of contention. Despite the review by Singletary [1] indicating that wider excisions are unlikely to reduce local recurrence rates, there remains considerable conflict among surgeons and radiation oncologists as to what is the optimum width of clear margin after breast conserving surgery. There has been increasing focus on trying to identify those patients who are at significant risk for local recurrence from radiological, pathological and molecular biology perspectives. The radiological issues have focused on the role played by magnetic resonance imaging and its value in identifying mammographically occult disease. There remain some radiologists who advocate its widespread use, but evidence of its value is limited [2]. Work by Tabar and coworkers [3] suggests there is a group of patients with widespread casting type microcalcification on mammograms; they consider this to represent neoductgenesis, and it was a poor prognostic sign in their series. Using all of the information that we are provided with by radiologists and incorporating mammographic patterns of cancer into prognosis remains challenging and is an area of controversy.

As well as margins, the pathologist assesses a variety of factors that have been shown to influence local recurrence, including histological grade and the presence of lymphatic vascular invasion. Even with accurate pathology, however, it is difficult to identify those who will develop local recurrence with any precision. For this reason, there has been a move to investigate molecular markers. Gene array profiles have been investigated recently but cannot yet accurately identify those patients at risk for local recurrence.

Therefore, the greatest influence on local recurrence after breast conserving surgery is currently the surgeon's ability to
Breast Cancer Research 2008, 10(Suppl 4):S2 (doi:10.1186/bcr2162)

reduce the volume of disease within the breast, to a level that can be adequately controlled by radiotherapy. Thus, the art of surgery and the ability of the surgeon to remove diseased tissue while retaining sufficient breast tissue to produce a satisfactory outcome is a major reason why such surgery is best carried out by those with a large volume of clinical experience.

\section{Competing interests}

The authors declare that they have no competing interests.

\section{Acknowledgement}

This article has been published as part of Breast Cancer Research Volume 10 Supplement 4, 2008: Controversies in Breast Cancer 2008. The full contents of the supplement are available online at http://breast-cancer-research.com/supplements/10/S4

\section{References}

1. Singletary SE: Surgical margins in patients with early-stage breast cancer treated with breast conservation therapy. $A m$ J Surg 2002, 184:383-393.

2. Houssami N, Ciatto S, Macaskill P, Lord SJ, Warren RM, Dixon $J M$, Irwig L: Accuracy and surgical impact of MRI in breast cancer staging: systematic review and meta-analysis in detection of multifocal and multicentric cancer. J Clin Oncol 2008 , 26:3248-3258

3. Tabar L, Tot T, Dean PB: Breast Cancer: Early Detection with Mammography. Casting Type Calcifications: Sign of a Subtype with Deceptive Features. New York, NY: Thieme Medical Publishers Inc.; 2007. 